\title{
Melkersson-Rosenthal syndrome: An unusual cause of intermittent raised hemidiaphragm?
}

\author{
Bilal H. Kirmani, MRCS, ${ }^{\mathrm{a}}$ Christopher M. Dobson, FRCP, FRCPath, ${ }^{\mathrm{b}}$ and Joseph Zacharias, FRCS (C-Th), ${ }^{\mathrm{a}}$ \\ Blackpool and Preston, United Kingdom
}

Melkersson-Rosenthal syndrome (MRS) is a rare dermatologic syndrome, characterized by the triad of chronic orofacial swelling involving one or both lips, relapsing facial nerve paralysis, and furrowed dorsum of the tongue (lingua plicata). The complete triad is only present in about $25 \%$ of cases. The orofacial edema affecting one or both lips is the dominant finding and may be the presenting sign in nearly half of all cases. Although the syndrome has been described involving other cranial nerves, we present a case of granulomatous cheilitis of the upper lip where there was a relapsing involvement of the phrenic nerve that was resistant to medical therapy.

\section{CLINICAL SUMMARY}

During routine dermatologic review, a 25-year-old nonsmoking woman with granulomatous cheilitis reported somnolence, headaches, nausea, and clamminess. Examination revealed decreased air entry at the right lung base, radiographically associated with a raised right hemidiaphragm (Figure 1, A). Ultrasonography confirmed absent excursion of the right hemidiaphragm with no subdiaphragmatic abnormality, and further imaging with high-resolution computed tomography demonstrated no intrathoracic tethering, atelectasis, lung fibrosis, mediastinal masses, or abdominal splinting. Transcutaneous nerve conduction studies some months later demonstrated normal phrenic motor latencies.

There was no history of preceding head, neck, or chest trauma. The patient had no respiratory symptoms, no other neurologic disturbances, and no clinical features of porphyria. Blood tests showed normal full blood cell count, urea level, electrolytes, liver function, calcium level, and serum angiotensin-converting enzyme level, with negative results for antineutrophil cytoplasmic autoantibodies and only weakly positive results for antinuclear antibodies (1:40). Sarcoidosis was therefore considered unlikely.

The patient had a history of granulomatous cheilitis from the age of 7 years, with granulomatous histology proven on labial biopsy. Crohn disease had been ruled out with upper and

\footnotetext{
From the Department of Cardiothoracic Surgery, ${ }^{a}$ Blackpool Victoria Hospital, Blackpool, United Kingdom; and the Department of Dermatology, ${ }^{\mathrm{b}}$ Royal Preston Hospital, Preston, United Kingdom.

Disclosures: Authors have nothing to disclose with regard to commercial support.

Received for publication Oct 17, 2010; accepted for publication Dec 8, 2010; available ahead of print Feb 10, 2011.

Address for reprints: Bilal H. Kirmani, MRCS, Blackpool Victoria Hospital, Cardiothoracic Surgery, Whinney Heys Rd, Blackpool, Lancashire FY3 8NR, UK

(E-mail: egocentric@doctors.net.uk)

J Thorac Cardiovasc Surg 2011;141:e27-8

$0022-5223 / \$ 36.00$

Copyright (C) 2011 by The American Association for Thoracic Surgery

doi:10.1016/j.jtcvs.2011.01.010
}

lower gastrointestinal endoscopies, including rectal biopsies. Although the patient did not have lingua plicata or facial nerve paralysis, a diagnosis of a monosymptomatic manifestation of MRS was made. Treatment had been composed of prednisolone and mesalamine (INN mesalazine) for 2 years, switched at 1 stage to clofazimine for 2 months. Subsequent withdrawal of mesalamine did not improve the raised hemidiaphragm.

It was considered that the diaphragmatic paralysis might be due to a neuropathy associated with the condition. Because the patient remained free of symptoms, however, a conservative approach was adopted.

Eighteen months later, the patient had increasing orthopnea and exertional dyspnea. Lung function tests demonstrated a significant orthostatic deterioration in forced expiratory volume in 1 second and forced vital capacity, and the patient was listed for diaphragmatic plication. She was not receiving any treatment for her cheilitis at that time. Routine radiography at preoperative assessment, however, revealed a normal position of the right hemidiaphragm (Figure 1, B). The procedure was therefore cancelled, and repeated radiography confirmed resolution. The patient's symptoms also resolved, with improvement in pulmonary function tests and a return to normal activities.

One year later, the patient had recurrent symptoms of breathlessness. During this interval, her cheilitis had shown intermittent exacerbations on a background of chronic inflammation. Chest radiography again revealed a raised hemidiaphragm (Figure 1,C), and lung function had once again deteriorated, despite concurrent medical immunomodulation aimed at the orofacial inflammation. On this occasion, the diaphragm remained fixed for several months, and diaphragmatic plication was carried out through a minithoracotomy to reduce hepatic intrathoracic encroachment.

\section{DISCUSSION}

Granulomatous cheilitis, whether in isolation or as part of MRS, may be a presenting feature of Crohn disease. MRS is usually limited in symptoms, only rarely presenting with the entire classic triad of orofacial granulomatosis, intermittent facial nerve paralysis, and lingua plicata. ${ }^{1}$ Extracranial mucocutaneous manifestations of the disease ${ }^{2}$ and other cranial nerve disorders have been described in the condition, ${ }^{3}$ but there have been no reports of extracranial neuropathies. One article described aberrance in the cardiac conducting system $^{4}$ causing heart block

Other causes for a mononeuropathy seem unlikely here. Mesalamine can cause neuropathy, but recrudescent 

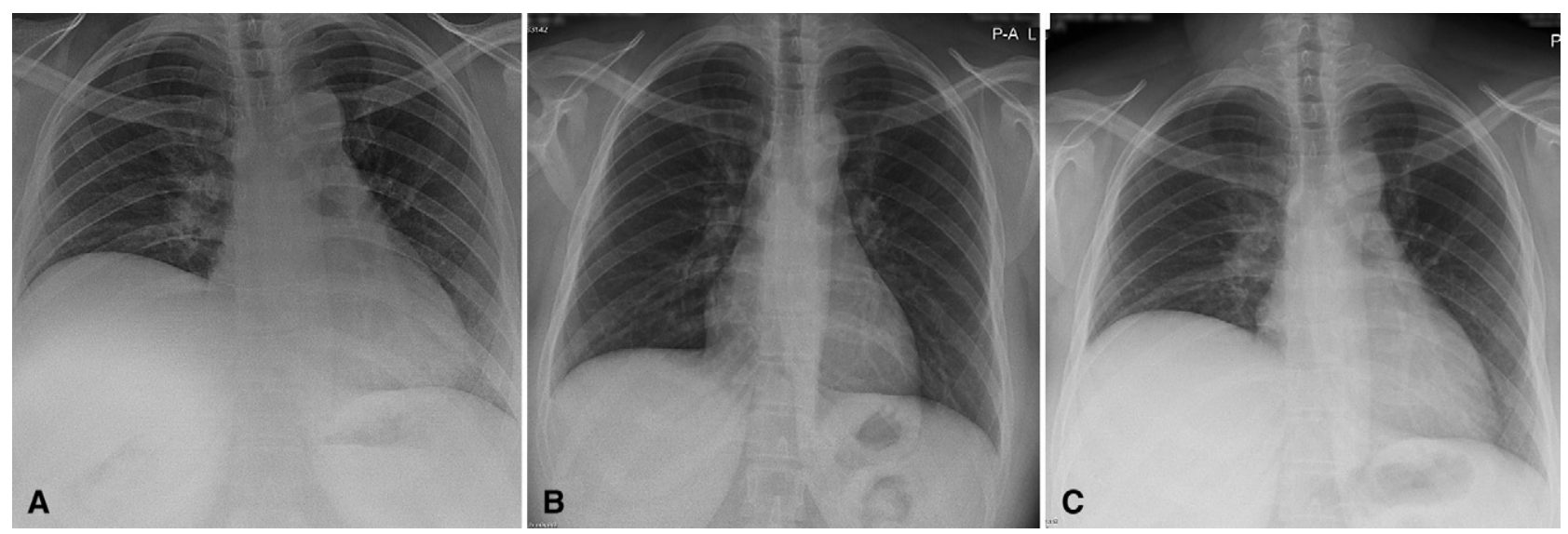

FIGURE 1. Intermittent raised hemidiaphragm at time of finding (A), improved at time of initial preoperative assessment and 18 months later (B), and raised again at 32 months $(\mathrm{C})$.

hemidiaphragm raise at one stage occurred some months after cessation of that drug. Likewise, the timing and brevity of exposure to clofazimine makes it an unlikely culprit.

We postulate that in this case of MRS intermittent diaphragmatic paralysis of unknown etiology may have been an unusual extracranial neuropathy. We suggest that the diagnosis be considered in other patients with peripheral neuropathies in the context of granulomatous cheilitis.

\section{References}

1. Ang KL, Jones NS. Melkersson-Rosenthal syndrome. J Laryngol Otol. 2002;116: 386-8.

2. Sbano P, Rubegni P, Risulo M, De Nisi MC, Fimiani M. A case of idiopathic granulomatous cheilitis and vulvitis. Int J Dermatol. 2007;46:720-1.

3. Aluclu MU, Keklikci U, Guzel A, Unlu K, Tatli M. Melkersson-Rosenthal syndrome with partial oculomotor nerve palsy. Ann Saudi Med. 2008;28:135-7.

4. Chan YC, Lee YS, Wong ST, Lam SP, Ong BK, Wilder-Smith E. MelkerrsonRosenthal syndrome with cardiac involvement. J Clin Neurosci. 2004;11: 309-11.

\title{
Staged repair of pectus excavatum during an aortic valve-sparing operation
}

\author{
Natacha Rousse, ${ }^{\mathrm{a}, \mathrm{b}}$ Francis Juthier, MD, PhD, ${ }^{\mathrm{b}}$ Alain Prat, MD, ${ }^{\mathrm{b}}$ and Alain Wurtz, MD, ${ }^{\mathrm{a}}$ Lille, France
}

Controversy remains regarding the concomitant repair of pectus excavatum and an aortic root aneurysm in patients with Marfan syndrome. The pectus deformity may impair optimal operative exposure of the aortic root, whereas cardiopulmonary bypass coagulopathy would increase bleeding after pectus excavatum repair. The concomitant

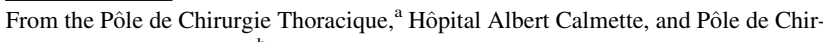
urgie Cardiovasculaire, ${ }^{\mathrm{b}}$ Hôpital Cardiologique, CHU de Lille, Lille, France. Disclosures: Authors have nothing to disclose with regard to commercial support. Received for publication Oct 7, 2010; revisions received Dec 17, 2010; accepted for publication Jan 10, 2011; available ahead of print March 14, 2011

Address for reprints: Alain Wurtz, MD, Pôle de Chirurgie Thoracique, Hôpital Albert Calmette, CHU de Lille, F59037, Lille Cedex, France (E-mail: alain.wurtz@ chru-lille.fr).

J Thorac Cardiovasc Surg 2011;141:e28-30

$0022-5223 / \$ 36.00$

Copyright (C) 2011 by The American Association for Thoracic Surgery doi:10.1016/j.jtcvs.2011.01.019
}

surgery requires (1) a minimal bleeding period during pectus correction, (2) optimal operative exposure during aneurysm repair, (3) efficient chest-wall stabilization using a device that allows urgent postoperative reentry or cardiopulmonary resuscitation maneuvers if needed, and (4) a satisfactory cosmetic result.

Our technique is a modified Ravitch procedure, with staged resection of the cartilages before and after aortic root aneurysm repair. The procedure starts with a midline presternal incision. The pectoralis muscles are reflected superiorly, and the rectus abdominis is detached inferiorly. The lower cartilages (fourth to sixth and extremities of the seventh) are subperichondrially resected, whereas the xyphoid process is preserved (Figure 1, A). After a median sternotomy, aneurysm repair is then performed under cardiopulmonary bypass. Last, after sternum closure, pectus repair is achieved by performing additional resection of 